\title{
Associations between cardiorespiratory fitness and the metabolic syndrome in British men
}

LEE INGLE ${ }^{1 *}$ PhD FESC; MICHELLE MELLIS² PhD; DAVID BRODIE PhD;

GAVIN R SANDERCOCK ${ }^{4} \mathrm{PhD}$

\section{*Address for correspondence}

1003 Don Building

Department of Sport, Health \& Exercise Science

University of Hull

Cottingham Road

Kingston-upon-Hull

HU7 6RX

United Kingdom

Tel: 01482463141

Fax: 01482463855

Email: L.Ingle@hull.ac.uk

2Leeds Beckett University, Carnegie Faculty, Leeds, United Kingdom (m.mellis@leedsbeckett.ac.uk)

${ }^{3}$ Buckingham New University, Faculty of Health, Bucks, United Kingdom (d.brodie@newbucks.ac.uk)

${ }^{4}$ Centre for Sport \& Exercise Sciences, University of Essex, Essex, United Kingdom (gavins@essex.ac.uk; 01206 872043)

Article type: Original

Running title: Fitness and Metabolic Syndrome

Conflicts of Interest \& Disclosures: None declared

Total Word Count: 2758

Keywords: Epidemiology; Risk Factors; Exercise; Exercise Testing 
"The Corresponding Author has the right to grant on behalf of all authors and does grant on behalf of all authors, an exclusive licence (or non exclusive for government employees) on a worldwide basis to the BMJ Publishing Group Ltd and its Licensees to permit this article (if accepted) to be published in HEART editions and any other BMJPGL products to exploit all subsidiary rights"

What is already known about this subject?

There is a strong association between high levels of cardio-respiratory fitness (CRF) and reduced risk of all-cause and cardiovascular mortality; these data mainly emanate from large North American databases. However, the associations of CRF with increasing age and changes in body composition with ageing have yet to be determined.

What does this study add?

In the largest study of its type in a UK population, we have shown that the prevalence of MetS is approximately one quarter of apparently healthy British men. Across increasing agestrata ( $20-69$ years), prevalence of MetS was 32 to $53 \%$ lower in those men with good CRF ("Fit"). The association between CRF and MetS is stronger in younger men and, while it weakens with age, the association remains independent of BMI for men aged $<50$ years.

How might it impact on clinical practice in the near future?

Public health messages should advocate the need for improving CRF alongside weight management for enhancing cardio-metabolic health. Inclusion of CRF assessments in UK health screening would provide greater insight into individualised metabolic health. 


\section{Abstract}

Background: Age and body mass index (BMI) are positively associated with the development of the metabolic syndrome (MetS). Cardiorespiratory fitness (CRF) can attenuate BMIrelated increases in prevalence of MetS, but the nature of this association across different age strata has not been fully investigated.

Aim: To identify the association between CRF and MetS prevalence across age-strata (2069 years) and determine whether associations are independent of BMI.

Methods: CRF was estimated from incremental treadmill exercise in British men attending preventative health screening. Participants were placed in four age strata $(20-39,40-49,50-$ 59 and 60-69 years) and classified as Fit or Unfit using age-related cut-offs. Presence of MetS was defined using the National Cholesterol Education Program Adult Treatment Panel III criteria.

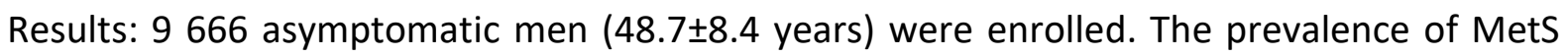
was $25.5 \%$ in all men, and ranged from $17.1 \%$ in $20-39$ year olds to $30.6 \%$ in $60-69$ year olds. Fit men's likelihood of meeting the criteria for MetS was half $(\mathrm{OR}=0.51,95 \% \mathrm{Cl}: 0.46-0.57)$ that of unfit men. The likelihood of MetS was 32-53\% lower across age strata in Fit, compared with Unfit men. Adjustment for BMI attenuated the association, though it remained significant in men aged $20-49$ years.

Conclusion: The cardio-metabolic benefits of CRF are independent of BMI particularly in men $<50$ years. Public health messages should emphasise the important role of CRF alongside weight management for enhancing cardio-metabolic health. (250 words) 


\section{Introduction}

Adults with low cardiorespiratory fitness (CRF) have an increased risk of premature all-cause (70\%) and cardiovascular mortality (56\%) compared with the highest. ${ }^{1}$ Despite the potential value of exercise testing in health surveillance and preventive healthcare ${ }^{2}$, CRF is not routinely assessed in UK health surveys, nor employed in health screening. Screening relies on identifying the presence and clustering of traditional cardiovascular disease risk factors. These factors may indicate a pre-diabetic state, termed the metabolic syndrome (MetS). The health implications ${ }^{3}$, correlates ${ }^{4}$ and antecedents ${ }^{5}$ of MetS are well described elsewhere. In the UK, the ageing population continues to see rises in body mass index $(\mathrm{BMI})^{6}$, which indicates that prevalence of MetS may increase in years to come if left unchecked.

The protection afforded by CRF occurs in a dose dependent fashion ${ }^{6}$. CRF can attenuate MetS risk ${ }^{7-10}$ but data describing CRF in UK adults are sparse ${ }^{11}$.The Aerobic Center Longitudinal Study based at the Cooper Clinic is perhaps the largest source of data showing the cross-sectional relationship between CRF and cardio-metabolic risk ${ }^{12}$. Earnest and colleagues $^{12}$ demonstrated that in 38,659 males and females, CRF demonstrated a strong inverse relationship with MetS after adjustment for BMI, smoking status, alcohol intake, and family history of cardiovascular disease. We aimed to determine the association between CRF and the prevalence of MetS across different age-strata of asymptomatic British men. These data are important as it is necessary to ascertain whether the strong inverse associations between CRF and MetS is maintained across the lifespan. We also attempted to determine the degree to which the association was independent from BMI. 


\section{Methods}

Ethical approval was granted by the Faculty of Society \& Health ethics committee, Buckinghamshire New University. Participants (aged 20-69 years) attended one of five Health \& Wellbeing clinics around the UK for a three-hour preventative health assessment between 2000 and 2009. Participants attended general health examinations as an annual benefit provided by their corporate wellness schemes. Each participant was instructed in their preassessment information pack to avoid any form of vigorous physical activity, alcohol and/or caffeinated beverages within the 24 hours prior to their assessment. Each participant signed and consented to the test battery and use of their data for research purposes.

\section{Anthropometric measurements}

Body mass was measured using digital scales (Marsden, UK) and recorded to the nearest 0.1 kg. Clothing was worn but shoes and belts were removed, and participants evacuated their bladder before stepping onto the scales. Scales were calibrated daily with a known weight and bi-annually by the manufacturer. Stature was measured using a stadiometer (Seca, Hamburg, Germany) and recorded to the nearest $0.1 \mathrm{~cm}$. Participants removed their shoes, stood on the stadiometer platform with feet together, and head in the Frankfort plane. Buttocks and scapulae were in contact with the back of the stadiometer, shoulders relaxed with hands and arms loosely to the sides, the measurement was taken on full inhalation. Body mass index (BMI), was subsequently reported as $\mathrm{kg} \cdot \mathrm{m}^{-2}$, then categorised into underweight $\left(n=4\right.$, cases removed), normal weight $\left(18.5-24.9 \mathrm{~kg} \cdot \mathrm{m}^{-2}\right)$, overweight $\left(25-29.9 \mathrm{~kg} \cdot \mathrm{m}^{-2}\right)$, and obese $\left(\geq 30 \mathrm{~kg} \cdot \mathrm{m}^{-2}\right)^{13}$. Waist circumference $(\mathrm{WC})$ was measured using a standard anthropo- 
metric flexible tape measure (Seca, Birmingham, UK), at minimal inspiration to the nearest $0.1 \mathrm{~cm}$, midway between the lowest rib and the iliac crest, which corresponded with the umbilical level in most participants.

Venous blood sampling

Participants presented in a fasted state (for the previous 12 hours) but ate a snack (fruit or muesli bar) prior to the exercise test. At the start of each assessment, fasted venous blood samples was obtained using vacutainer tubes and heparinised whole blood was analysed using the Piccolo blood chemistry analyser (Abaxis, USA). The following analytes were measured: glucose, total cholesterol (TC), low density lipoprotein (LDL), high density lipoprotein (HDL), triglycerides, and TC/HDL ratio.

\section{Exercise tolerance test}

Resting blood pressure was measured using a manual system (Accoson Duplex Aneroid Model, AC Cosser \& Son Ltd, UK). Participants positioned themselves on the T2100 treadmill (GE Healthcare, UK), and undertook an incremental exercise test using the Bruce protocol. Blood pressure was monitored at the second minute of each stage using the automated Tango stress test monitor (Suntech Medical, Oxfordshire, UK). Rating of perceived exertion (RPE) was recorded at the end of each stage using the 6-20 Borg Scale. The electrocardiogram (ECG) was monitored throughout the test. Participants exercised until they attained $\geq 85 \%$ of their age-predicted maximum heart rate determined by the 220 -age formula, or met any of the ACSM termination criteria. Peak oxygen uptake was estimated and reported 
in $\mathrm{ml} \cdot \mathrm{kg}^{-1} \cdot \mathrm{min}^{-1} 14$. Data were categorised by 10 -year age strata, and peak oxygen uptake $\left(\mathrm{ml} \cdot \mathrm{kg}^{-1} \cdot \mathrm{min}^{-1}\right)$ was classified as 'Fit' or 'Unfit' based on the Cooper Institute age- and sexspecific cut-offs for $\mathrm{CRF}^{15}$.

\section{Data treatment}

All participants with a diagnosis of cardio-metabolic disease were excluded from the analysis. We defined the presence of Metabolic Syndrome (MetS) using the National Cholesterol Education Program Adult Treatment Panel III (NCEP ATP III) criteria ${ }^{16}$ : Waist circumference $>102 \mathrm{~cm}$; serum triglycerides $>\left.1.7 \mathrm{mmol} \cdot\right|^{-1}$; $\mathrm{HDL}$-cholesterol: $<1.03 \mathrm{mmol} \cdot \mathrm{I}^{-1}$; systolic blood pressure $\geq 130 \mathrm{mmHg}$ or diastolic blood pressure $\geq 85 \mathrm{mmHg}$; fasting serum glucose $>5.6$ $\mathrm{mmol} \cdot \mathrm{f}^{-1}$ or current treatment for diabetes. Each MetS component was classified as either present or absent according to the above criteria. We calculated the number of MetS components present for each participant to provide an ordinal measure of cardio-metabolic health. Presence of $\geq 3$ components was used to indicate presence of the MetS .

\section{Data Analysis}

SPSS version 22.0 (SPSS an IBM Company, IBM Ltd. NY, USA) was used to analyse the data. An alpha level of $P<0.05$ was accepted as significant. All variables were checked for normality using Kolmogorov-Smirnov tests. All continuous variables in Table 1 were normally distributed. Descriptive statistics were performed to identify means, standard deviations, and 95\% confidence intervals ( $\mathrm{Cl}$ ). Area level deprivation was determined by home postal codes using the English Indices of Deprivation (EID) ${ }^{17}$. A higher EID is indicative of a more deprived 
lower super output area. We compared socio-demographic and anthropometric values between participants classified as 'Fit' (versus 'Unfit') using independent $t$-tests for continuous variables and using $\chi^{2}$ tests for categorical variables.

We compared the prevalence of MetS components categorised as present across age groups using $\chi^{2}$ test and one-way analysis of variance (ANOVA). The number of MetS components present between age-groups was analysed using the Kruskal-Wallace $h$-test. We used binary logistic regression analysis to determine the likelihood of a diagnosis of MetS within each age strata according to CRF. Using 'Unfit' as the referent category, we calculated the odds $(\mathrm{OR} ; 95 \% \mathrm{Cl})$ of presence of MetS within each age strata in participants classified as 'Fit'. These estimates were adjusted for smoking status, area-level deprivation, and BMI. We also examined prevalence of MetS (\%) based on a quintile distribution of CRF (Figure 1).

\section{Results}

9666 asymptomatic men (48.7 \pm 8.4 years) were enrolled. Mean estimated peak oxygen uptake, was $38.7( \pm 9.9) \mathrm{ml} \cdot \mathrm{kg}^{-1} \cdot \mathrm{min}^{-1}$ and $23.8 \%(n=2401)$ of participants were classified as Unfit (Table 1). More than half, (54\%) of the sample were overweight; and a further $18 \%$ were obese. Unfit men had significantly higher waist circumference, blood pressure, plasma triglycerides, and lower levels of plasma HDL (all $P<0.001)$. Fasting plasma glucose $(P=0.075)$ and LDL $(P=0.605)$ did not differ significantly according to CRF. 
Table 2 shows that $25.5 \%$ of all participants met the criteria for MetS, but prevalence varied by age group from $17.1 \%$ in those aged $20-39$ years, to $30.6 \%$ in the $60-69$-years category. When presenting prevalence (\%) of MetS based on a quintile distribution of CRF (Figure 1), we noted an inverse linear association. MetS prevalence was $33.1 \%$ in the least fit group which reduced in a step-wise manner to the highest fit group (prevalence $16.5 \%, O R=0.71$ [95\% $\mathrm{Cl} 0.61-0.83], P<0.001)$ after adjustment for age and BMI.

Across all ages, the likelihood of MetS was significantly lower ( $\mathrm{OR}=0.51,95 \% \mathrm{Cl}: 0.46-0.57)$ in Fit men. After adjusting for age, deprivation index, smoking status, and BMI; the likelihood of MetS in Fit men remained lower than those who were Unfit (OR=0.73; 95\%Cl:0.65-0.82; Table 3). Being classified as "Fit" significantly reduced the likelihood of MetS across the majority of age strata with or without additional adjustment for BMI. Applying Model 1 in men aged 60-69 years, being "Fit" was associated with a 32\% lower odds of MetS (OR=0.68, 95\% $\mathrm{Cl}: 0.48-0.98 ; P=0.004$ ), but when this estimate was corrected for $\mathrm{BMI}$ (Model 2), there was no longer a significant difference in the likelihood of MetS in this age strata $(P=0.319)$.

\section{Discussion}

More than one-quarter (25.5\%) of 9666 asymptomatic males comprising our sample met the ATP III Criteria ${ }^{15}$ for presence of the metabolic syndrome (MetS) which is comparable with estimates (29-34\%) from representative samples of US adult men. ${ }^{18}$

The prevalence of MetS was higher than has been reported previously in UK adults. Brunner et al. ${ }^{4}$ reported that $11.7 \%$ of civil servants (age 30-63 years) surveyed between 1991 and 
1993 met their definition of MetS. Hyppönen et al. ${ }^{19}$ identified MetS in 9.7\% of ( $n=6$ 810) 45 year old men with a prevalence of overweight and obesity comparable to that of the present study. Neither study included objective assessments of CRF or physical activity. Hyppönen et al. ${ }^{19}$ found self-reported physical activity was negatively associated with MetS, whereas Brunner et al. ${ }^{4}$ found no significant association. Neither of these large cohort studies examined the role of CRF.

\section{Cardiorespiratory Fitness and Metabolic Syndrome}

Fit men had significantly lower mean values for all MetS components (except glucose, $P=0.075)$, fewer cardio-metabolic risk factors, and had a lower prevalence of MetS when compared with men classified Unfit. The association between CRF and MetS remained significant when adjusting for $\mathrm{BMI}^{10}$. LaMonte et al. ${ }^{8}$ found MetS incidence was $53 \%$ lower in men within the highest tertile of CRF compared with the least fit. This estimate was not adjusted for BMI, but can be compared with our unadjusted estimate of $49 \%$. Incidence of MetS in the oldest group (60-69 years), was nearly double that of the youngest participants (20-29 years), and there was a significant increase in each MetS component across agestrata. Our findings are in agreement with studies describing an age-related increase in the prevalence of $\mathrm{MetS}^{20}$. To expand on previous findings we assessed whether the association between CRF and MetS differed according to age. The inverse association between higher levels of CRF and lower prevalence of MetS was most evident in younger men (54\% lower likelihood) but persisted across all age groups, including those age 60-69 years (32\%). Like MetS, the prevalence of obesity increased with age (Table 2). Adjusting for BMI attenuated the association between CRF and MetS but remained significant (33-34\% lower) in men 
aged $20-49$ years. The association was not statistically significant in $60-69$ year-olds. Fit men of this age still had $16-17 \%$ lower risk of MetS than those who were less fit. These findings concur with previous studies that have used directly measured ${ }^{82} \mathrm{CRF}$.

The MRC Ely Study examined the association between a continuous metabolic risk score, physical activity energy expenditure (PAEE), and CRF in healthy men (54 years) ${ }^{22}$. The robust, objective assessment of PAEE used was in contrast to the estimations of CRF from submaximal exercise. Franks et al. ${ }^{23}$ showed that the association between a metabolic risk score and PAEE was three times stronger than what it shared with CRF. While Ekelund et al. ${ }^{22}$ found a negative association between metabolic risk score and CRF, they reported that the association was no longer significant after adjusting for PAEE. The authors acknowledged the role of measurement error in their findings. Estimating CRF from sub-maximal exercise is associated with large random errors. Cycle ergometry may systematically underestimate CRF. Using data reported by the authors, we estimate that a healthy male, aged 54 years of age, would have a peak oxygen uptake of approximately $32 \pm 7 \mathrm{ml} \cdot \mathrm{kg}^{-1} \cdot \mathrm{min}^{-1}$. This value is close to our Unfit group and below the normal range of values expected for men of this age $^{15}$.

Objectively measured CRF 'outperforms' physical activity ${ }^{24}$ and more-traditional cardiovascular disease risk factors as an indicator of health ${ }^{7}$, and as a predictor of all-cause and cardiovascular mortality ${ }^{20}$. These studies in conjunction with our findings provide further evidence to support public health messages emphasising the importance of improving CRF for promoting cardio-metabolic health. Unlike US guidelines ${ }^{25}$, current UK messages largely focus on the promotion of physical activity per se, and in many cases, the relatively weak association it shares with weight status and weight gain. 
The greatest risk of developing metabolic abnormalities, MetS, and CVD, is universally reported in individuals with the lowest CRF values ${ }^{126}$. Relatively modest increases in physical activity in adults with initially low CRF can result in observable gains in CRF associated with reductions in morbidity and mortality ${ }^{9}$. Current guidelines for minimum physical activity levels in adults were established, in part, on the evidence of such gains in the least fit individuals. ${ }^{25}$ This is not to say that physical activity and BMI do not play an important role in metabolic health ${ }^{27}$ and cardiovascular disease ${ }^{2128}$. Due, however, to the difficulties in measuring physical activity and the modest reductions in BMI in response to physical activity, objectively measured CRF appears a more suitable outcome measure.

Individuals with higher fitness levels are more likely to be involved in either, or in combination, a more habitually active lifestyle and/or participate in regular structured sporting activities. The umbrella term MetS is associated with oxidative stress, inflammation, and insulin resistance; it has been well established that exercise and increased physical activity are able to boost antioxidant capacity, and induce anti-inflammatory effects ${ }^{29}$. Exercise training positively regulates fat and glucose metabolism, and improves both blood pressure control and insulin action ${ }^{30}$.

\section{Limitations}

These data are drawn from an opportunistic sample of men attending private health screening at entry to a preventive health programme and may not be nationally representative sample. The mean area-level deprivation score for the sample was low, indicating participants lived in relatively affluent areas of the UK. MetS is positively associated with higher 
levels of deprivation, so the prevalence may be higher in a nationally representative sample. The fact that all participants were voluntarily participating in a preventive healthcare programme may have biased the sample either towards health conscious individuals which would likely produce a lower prevalence of MetS than expected. Alternatively, the preventive screening and healthcare may have attracted individuals with existing health concerns or those advised to improve their health by family, friends or a medical practitioner. Despite such potential biases, the sample means for health indicators such as blood pressure, BMI, and the proportion of overweight and obese, are very similar to values from nationally representative samples reported as part of UK health surveillance ${ }^{31}$.

The use of estimated peak oxygen uptake is also a limitation of the study. There are no reference data for CRF in UK adults with which to compare the present values. However, the estimates of CRF reported here are comparable with studies using expired gas analysis ${ }^{9}$. Age-related cut-offs ${ }^{31}$ for low fitness are based on values approximating the $20^{\text {th }}$ percentile of the reference population, the proportion of men classified as unfit (24.5\%) also support the validity of our approach ${ }^{67}$. It should also be noted that the association between MetS and CRF is not markedly different between studies reporting estimated or measured peak oxygen uptake.

We defined MetS using the criteria developed by the NCEP as opposed to international criteria ${ }^{16}$, as most studies investigating CRF and MetS have emanated from North America. There is relatively high concordance between these criteria when applied in populations similar to the present sample ${ }^{28}$.

We also acknowledge the cross-sectional design of the study; thus cause and effect cannot be ascertained. Furthermore, we cannot generalise our findings to the female population. 
Finally, we did not adjust for variations in dietary intake or socioeconomic status which may have acted to confound the associations.

\section{Conclusion}

The value of assessing CRF in asymptomatic adults is well established, yet CRF remains absent from UK health surveillance and screening. The negative association between CRF and metabolic risk is well established as is the age-related increase in MetS.

The present study demonstrated the expected increase in MetS prevalence associated with advancing age. Across the age-strata studied (20 - 69 years), prevalence was 32 to $53 \%$ lower in those men with good CRF ("Fit"). The association between CRF and MetS is stronger in younger men and, while it weakens with age, the association between CRF and MetS remains independent of BMI for men aged 20-49 years. Public health messages should emphasise the importance of improving CRF alongside weight management for enhancing cardio-metabolic health. Inclusion of CRF assessments in UK health screening would provide greater insight into the metabolic health of asymptomatic men.

\section{Acknowledgements:}

The authors would like to thank the staff and management of Nuffield Healthcare for collecting and providing us with access to the data. We would also like to thank Dr Sean Wheatley for his assistance with data presentation. 


\section{Conflicts and competing interests:}

Authors: Sandercock, Mellis, Brodie and Ingle declare that they have no conflicts of interest and no competing interests.

\section{Contributorship:}

$\mathrm{LI}$ and GS led the project and were responsible for research design, data analysis and drafting the manuscript; $\mathrm{MM}$ and $\mathrm{DB}$ were responsible for data acquisition and editing the manuscript.

Funding: No funding was required

\section{Ethical Approval:}

Ethical approval was granted by the Faculty of Society \& Health ethics committee, Buckinghamshire New University. 


\section{References}

1. Kodama S, Saito K, Tanaka S, et al. Cardiorespiratory Fitness as a Quantitative Predictor of AllCause Mortality and Cardiovascular Events in Healthy Men and Women A Meta-analysis. Jama-J Am Med Assoc 2009;301(19):2024-35.

2. Kavanagh T, Mertens DJ, Hamm LF, et al. Prediction of long-term prognosis in 12169 men referred for cardiac rehabilitation. Circulation 2002;106(6):666-71.

3. Pyorala K, Qiao Q, Gao WG, et al. Metabolic syndrome in non-diabetic Europeans: Relation to cardiovascular mortality. Atherosclerosis Supp 2006;7(3):154-54.

4. Brunner EJ, Marmot MG, Nanchahal K, et al. Social inequality in coronary risk: central obesity and the metabolic syndrome. Evidence from the Whitehall II study. Diabetologia 1997;40(11):1341-49.

5. Ekelund U, Brage S, Franks PW, et al. Physical activity energy expenditure predicts progression toward the metabolic syndrome independently of aerobic fitness in middle-aged healthy Caucasians - The Medical Research Council Ely Study. Diabetes Care 2005;28(5):1195-200.

6. HSIC. Statistics on Obesity, Physical Activity \& Diet: England 2015. . Secondary Statistics on Obesity, Physical Activity \& Diet: England 2015. 2015. http://www.hscic.gov.uk/catalogue/PUB16988/obes-phys-acti-diet-eng-2015.pdf.

7. Ortega FB, Cadenas-Sanchez $C$, Sui $X$, et al. Role of Fitness in the Metabolically Healthy but Obese Phenotype: A Review and Update. Prog Cardiovasc Dis 2015;58(1):76-86.

8. LaMonte MJ, Barlow CE, Jurca R, et al. Cardiorespiratory fitness is inversely associated with the incidence of metabolic syndrome: a prospective study of men and women. Circulation 2005;112(4):505-12.

9. Lee DC, Sui XM, Church TS, et al. Changes in Fitness and Fatness on the Development of Cardiovascular Disease Risk Factors Hypertension, Metabolic Syndrome, and Hypercholesterolemia. J Am Coll Cardiol 2012;59(7):665-72.

10. Katzmarzyk PT, Church TS, Janssen I, et al. Metabolic syndrome, obesity, and mortality: impact of cardiorespiratory fitness. Diabetes Care 2005;28(2):391-7.

11. O'Donovan G, Hillsdon M, Ukoumunne OC, et al. Objectively measured physical activity, cardiorespiratory fitness and cardiometabolic risk factors in the Health Survey for England. Prev Med 2013;57(3):201-05.

12. Earnest $\mathrm{CP}$, Artero EG, Sui $\mathrm{X}$, et al. Maximal estimated cardiorespiratory fitness, cardiometabolic risk factors, and metabolic syndrome in the aerobics center longitudinal study. Mayo Clin Proc 2013;88(3):259-70.

13. WHO. Obesity: preventing and managing the global epidemic. Report of a WHO Consultation. WHO Technical Report Series 894. Geneva: World Health Organization, 2000.

14. Bruce RA, Kusumi F, Hosmer D. Maximal oxygen intake and nomographic assessment of functional aerobic impairment in cardiovascular disease. Am Heart J. 1973; 85(4):546-62.

15. Cooper_Institute. Physical Fitness Specialist Certification Manual The Cooper Institute for Aerobics Research. In: Heyward V, ed. Advanced Fitness Assessment and Exercise Prescription Champaign, IL.: Human Kinetics, 2010:5430589.

16. Alberti KGMM, Eckel RH, Grundy SM, et al. Harmonizing the Metabolic Syndrome A Joint Interim Statement of the International Diabetes Federation Task Force on Epidemiology and Prevention; National Heart, Lung, and Blood Institute; American Heart Association; World Heart Federation; International Atherosclerosis Society; and International Association for the Study of Obesity. Circulation 2009;120(16):1640-45.

17. DCLG. The English Indices of Deprivation 2007: Summary. Communities and Local Government Publications. Wetherby, UK., 2007.

18. Mozumdar A, Liguori G. Persistent Increase of Prevalence of Metabolic Syndrome Among US Adults: NHANES III to NHANES 1999-2006. Diabetes Care 2011;34(1):216-19. 
19. Hypponen E, Boucher BJ, Berry DJ, et al. 25-hydroxyvitamin D, IGF-1, and metabolic syndrome at 45 years of age: a cross-sectional study in the 1958 British Birth Cohort. Diabetes 2008;57(2):298-305.

20. Roberson LL, Aneni EC, Maziak W, et al. Beyond BMI: The "Metabolically healthy obese" phenotype \& its association with clinical/subclinical cardiovascular disease and all-cause mortality - a systematic review. BMC Public Health 2014;14:14.

21. Church TS, Finley $C E$, Earnest $C P$, et al. Relative associations of fitness and fatness to fibrinogen, white blood cell count, uric acid and metabolic syndrome. Int J Obes Relat Metab Disord 2002;26(6):805-13.

22. Ekelund U, Brage S, Franks PW, et al. Physical activity energy expenditure predicts progression toward the metabolic syndrome independently of aerobic fitness in middle-aged healthy Caucasians: the Medical Research Council Ely Study. Diabetes Care 2005;28(5):1195-200.

23. Franks PW, Ekelund U, Brage $S$, et al. Does the association of habitual physical activity with the metabolic syndrome differ by level of cardiorespiratory fitness? Diabetes Care 2004;27(5):1187-93.

24. Williams PT. Physical fitness and activity as separate heart disease risk factors: a meta-analysis. Med Sci Sport Exer 2001;33(5):754-61.

25. Haskell WL, Lee IM, Pate RR, et al. Physical activity and public health - Updated recommendation for adults from the American college of sports medicine and the American heart association. Circulation 2007;116(9):1081-93.

26. Kokkinos P, Myers J. Exercise and Physical Activity Clinical Outcomes and Applications. Circulation 2010;122(16):1637-48.

27. Earnest CP, Artero EG, Sui XM, et al. Maximal Estimated Cardiorespiratory Fitness, Cardiometabolic Risk Factors, and Metabolic Syndrome in the Aerobics Center Longitudinal Study. Mayo Clin Proc 2013;88(3):259-70.

28. Aspenes ST, Nilsen TI, Skaug EA, et al. Peak oxygen uptake and cardiovascular risk factors in 4631 healthy women and men. Med Sci Sports Exerc 2011;43(8):1465-73.

29. Dulloo AG, Montani JP. Pathways from dieting to weight regain, to obesity and to the metabolic syndrome: an overview. Obesity Rev 2015; 1: 1-6.

30. Golbidi, S, Mesdaghina A, Laher I. Exercise in the Metabolic Syndrome, Oxidative Med Cell Longev, 2012, 349710.

31. NOO. UK and Ireland prevalence trends. In: NOO, editor: Public Health England, 2015. 

Table 1. Demographic, anthropometric, and metabolic characteristics of 9666 British men attending preventative health screening between 2000 and 2009.

\begin{tabular}{|c|c|c|c|c|c|c|c|}
\hline \multirow[t]{2}{*}{$\begin{array}{l}\text { Cardiorespiratory Fitness } \\
\text { Classification }\end{array}$} & \multirow[b]{2}{*}{$\begin{array}{l}\text { Mean } \\
\text { or } \%\end{array}$} & \multirow{2}{*}{$\begin{array}{c}\text { All } \\
(9666) \\
\text { (SD) }\end{array}$} & \multicolumn{2}{|c|}{$\begin{array}{c}\text { Fit } 76.2 \% \\
\text { (7 265) }\end{array}$} & \multicolumn{2}{|c|}{$\begin{array}{l}\text { Unfit 24.8\% } \\
\text { (2 401) }\end{array}$} & \multirow[t]{2}{*}{$P$-value } \\
\hline & & & $\begin{array}{l}\text { Mean } \\
\text { or } \%\end{array}$ & (SD) & $\begin{array}{l}\text { Mean } \\
\text { or \% }\end{array}$ & (SD) & \\
\hline English Index of Deprivation & 10.6 & (8.2) & 10.6 & $(8.0)$ & 10.7 & (8.6) & 0.142 \\
\hline Age (years) & 48.7 & (8.4) & 49.5 & $(8.3)$ & 46.6 & (8.4) & $<0.001$ \\
\hline Stature $(m)$ & 1.78 & $(0.66)$ & 1.79 & $(0.65)$ & 1.79 & $(0.66)$ & $<0.001$ \\
\hline Weight (kg) & 86.6 & (12.5) & 85.6 & (11.8) & 90.2 & (14.0) & $<0.001$ \\
\hline BMI $\left(\mathrm{kg} \cdot \mathrm{m}^{-2}\right)$ & 27.1 & (3.5) & 26.8 & (3.3) & 28.2 & (3.5) & $<0.001$ \\
\hline Overweight (\%) & 54.3 & & 54.9 & & 52.0 & & $0.405^{*}$ \\
\hline Obese (\%) & 17.8 & & 15.2 & & 16.4 & & $<0.001^{*}$ \\
\hline 'Waist Circumference $(\mathrm{cm})$ & 94.3 & $(10.0)$ & 93.4 & (9.5) & 97.4 & $(10.0)$ & $<0.001$ \\
\hline $\mathrm{VO}_{2 \text { peak }}\left(\mathrm{ml} \cdot \mathrm{kg}^{-1} \cdot \mathrm{min}^{-1}\right)$ & 38.7 & (9.9) & 41.2 & $(8.0)$ & 28.1 & (3.8) & $<0.001$ \\
\hline Current Smokers (\%) & 8.6 & & 8.4 & & 9.0 & & 0.103 \\
\hline ‡SBP (mmHg) & 125.7 & (12.5) & 125.2 & (12.5) & 127.1 & (12.5) & $<0.001$ \\
\hline${ }^{\ddagger} \mathrm{DBP}(\mathrm{mmHg})$ & 81.2 & $(8.2)$ & 81.0 & (8.1) & 82.3 & (8.3) & $<0.001$ \\
\hline FFasting Glucose $\left(\mathrm{mmo} \cdot \cdot^{-1}{ }^{-1}\right)$ & 5.47 & $(0.74)$ & 5.4 & $(0.72)$ & 5.5 & $(0.83)$ & 0.075 \\
\hline $\operatorname{LDL}\left(\left.\mathrm{mmol} \cdot\right|^{-1}\right)$ & 3.36 & $(0.86)$ & 3.4 & $(0.87)$ & 3.4 & $(0.86)$ & 0.605 \\
\hline${ }^{ \pm} \mathrm{HDL}\left(\mathrm{mmol} \cdot \mathrm{l}^{-1}\right)$ & 1.40 & $(0.34)$ & 1.4 & $(0.34)$ & 1.3 & $(0.34)$ & $<0.001$ \\
\hline${ }^{\prime}$ Triglycerides $\left(\mathrm{mmol} \cdot \mathrm{l}^{-1}\right)$ & 1.46 & $(0.96)$ & 1.4 & $(0.91$ & 1.6 & $(0.96$ & $<0.001$ \\
\hline
\end{tabular}

Data presented as mean (SD) or \%; BMI - Body Mass Index; Overweight BMI 25.0-29.9 $\mathrm{kg} \cdot \mathrm{m}^{-2}$; Obese - BMI $>29.9 \mathrm{~kg} \cdot \mathrm{m}^{-2 ;} \mathrm{VO}_{2 \text { peak }}\left(\mathrm{ml} \cdot \mathrm{kg}^{-1} \cdot \mathrm{min}^{-1}\right)$ - peak oxygen consumption during symptom limited treadmill exercise; SBP - Systolic Blood Pressure; DBP - Diastolic Blood Pressure. LDL - Low Density Lipoprotein; HDL - High Density Lipoprotein. ${ }^{\ddagger}$-Indicates component of Metabolic Syndrome (MetS). $P$-values determined from independent t-test (Fit versus Unfit) or * $\chi^{2}$ test. 
Table 2. Components and prevalence of NCEP ATP III defined metabolic syndrome in 9666 British men

\begin{tabular}{|c|c|c|c|c|c|c|}
\hline & All & $20-39$ & $40-49$ yrs & $50-59$ yrs & $60-69$ yrs & $P$-value \\
\hline $\begin{array}{l}\text { Waist Circumference (\%) (>102 } \\
\mathrm{cm})\end{array}$ & 50.5 & 39.1 & 48.8 & 54.1 & 58.4 & $<0.001$ \\
\hline $\begin{array}{l}\text { Blood Pressure (\%) } \\
\text { (>135/80 mmHG) }\end{array}$ & 47.9 & 36.1 & 43.9 & 53.1 & 59.9 & $<0.001$ \\
\hline $\begin{array}{l}\text { Plasma Glucose }(\%) \\
\left(>\left.6.1 \mathrm{mmol} \cdot\right|^{-1}\right)\end{array}$ & 39.4 & 29.4 & 37.1 & 43.8 & 45.6 & $<0.001$ \\
\hline $\begin{array}{l}\text { Plasma Triglycerides }(\%)(>1.7 \\
\left.\mathrm{mmol} \cdot \mathrm{l}^{-1}\right)\end{array}$ & 28.5 & 26.3 & 29.7 & 29.9 & 21.3 & $<0.001$ \\
\hline $\begin{array}{l}\text { HDL (\%) } \\
\left(<\left.1.034 \mathrm{mmol} \cdot\right|^{-1}\right)\end{array}$ & 13.5 & 13.9 & 14.6 & 12.6 & 12.3 & 0.044 \\
\hline Prevalence of MetS (\%) & $25.5 \%$ & $17.1 \%$ & $24.1 \%$ & $28.5 \%$ & $30.1 \%$ & $<0.001$ \\
\hline
\end{tabular}

Legend: HDL - high density lipoprotein; NCEP ATP - National Cholesterol Education Program (NCEP) Expert Panel on Detection, Evaluation, and Treatment of High Blood Cholesterol in Adults (Adult Treatment Panel III) P-values correspond to statistical significance for main effect on one-way ANOVA. 
Table 3. Likelihood of the Metabolic Syndrome (NCEP ATP III Criteria) according to cardiorespiratory fitness in 9666 British men

\begin{tabular}{|c|c|c|c|c|c|}
\hline & & $\begin{array}{l}\text { Model 1: } \\
\text { OR (95\%Cl) }\end{array}$ & $P$-value & $\begin{array}{l}\text { Model } 2 \text { : } \\
\text { OR }(95 \% \mathrm{Cl})\end{array}$ & $P$-value \\
\hline All & Unfit & 1.00 & & 1.00 & \\
\hline$(n=9666)$ & Fit & $0.51(0.46-0.57)$ & $<0.001$ & $0.73(0.65-0.82)$ & $<0.001$ \\
\hline \multirow[t]{2}{*}{ Age 20-39 } & Unfit & 1.00 & & 1.00 & \\
\hline & Fit & $0.46(0.33-0.62)$ & $<0.001$ & $0.67(0.47-0.97)$ & $<0.001$ \\
\hline \multirow[t]{2}{*}{ Age 40-49 } & Unfit & 1.00 & & 1.00 & \\
\hline & Fit & $0.47(0.41-0.55)$ & $<0.001$ & $0.66(0.48-0.78)$ & $<0.001$ \\
\hline \multirow[t]{2}{*}{ Age 50-59 } & Unfit & 1.00 & & 1.00 & \\
\hline & Fit & $0.54(0.46-0.64)$ & $<0.001$ & $0.83(0.68-1.02)$ & 0.072 \\
\hline \multirow[t]{2}{*}{ Age 60-69 } & Unfit & 1.00 & & 1.00 & \\
\hline & Fit & $0.68(0.48-0.98)$ & 0.004 & $0.84(0.54-1.28)$ & 0.319 \\
\hline
\end{tabular}

Legend: NCEP ATP III - National Cholesterol Education Program (NCEP) Expert Panel on Detection, Evaluation, and Treatment of High Blood Cholesterol in Adults (Adult Treatment Panel III)

$\mathrm{OR}=$ Odds ratio; Fit or Unfit based on estimated $\mathrm{VO}_{2}$ peak above or below (respectively) the Cooper Institute age- and sex-specific cut-offs for poor cardiorespiratory fitness

Model 1. Adjusted for age, smoking status, area level deprivation;

Model 2. Adjusted for age, smoking status, area level deprivation, and body mass index $\left(\mathrm{kg} \cdot \mathrm{m}^{-2}\right)$. 